\title{
Physical Ergonomics Contribution to Health Workers' Well-Being: a Triage Station Analysis
}

\author{
M. Micheletti Cremasco ${ }^{1-2}, A, \operatorname{Re}^{1-3}, C$. Occelli ${ }^{1-3}$ \\ 1 LIDEA - Laboratorio InterDipartimentale di Ergonomia Applicata. E-mail:margherita.micheletti@unito.it \\ 2 Life Sciences and Systems Biology Dept - University of Torino \\ 3 Psychology Dept - University of Torino
}

KEY WORDS: ergonomics, emergency, Balance Theory.

\section{Introduction}

Many studies point out that stress considerably affects health workers, particularly in hospitals (Adriaenssens et al., 2011; European Agency for Safety and Health at Work, 2010). The present study was carried out in collaboration with the Emergency Department of a hospital located in Piedmont where workers presented high discomfort levels. Ergonomic intervention appears to be particularly appropriate to the objective of work stress primary prevention, since it includes the technical component (equipment), environmental aspects (appropriateness and functionality of spaces) and organisational aspects (rules and procedures). Non-integration of these components increases stress for operators both directly, by widening the gap between environmental demands and the ability of workers to meet them, and indirectly, as critical elements increase the risk level for patients, thus adding on to the operators' responsibilities. The study was conducted within the methodological framework of ergonomic analysis of work activity, with the aim of detecting the most critical environmental, instrumental and organisational conditions. In particular, the part of the project being dealt with here is concerned with the triage station, considered one of the most critical situations both from the point of view of operator-patient interaction and from that of the numerous interactions with different services and structures. Since some critical elements are inherent to Emergency services and, although detectable, they cannot be eliminated, this study has used the Balance Theory of Job Design (Smith and Carayon-Sainfort, 1989) as a theoretical framework for work analysis (Fig.1), because it points out that, even where eliminating all negative aspects is impossible, headway can still be made by highlighting the aspects that can be worked on.

\section{Materials and Methods}

\section{Physico-environmental analysis}

As Thomson maintains (1972), the workplace should be

consistent both with user's and with system performance

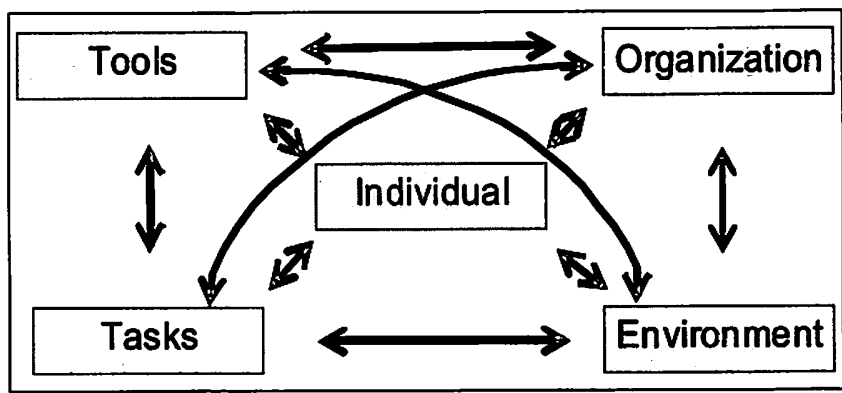

Fig. 1. Balance Theory of Job Design (Smith and Carayon-Sainfort, 1989).

needs. In assessing the health operator's workstation with reference to the tasks to be carried out, it was checked that what the operator must see (patients, colleagues, information, tools) was properly visible, what the operator must hear (doorbells, entryphones, verbal communication) was properly audible, what the operator must handle (controls, tools, auxiliary equipment) was easily accessible. The workstation was therefore analysed particularly through the analysis of the physical and functional environment, the workstation metrical data measurement and the equipment analysis in terms of size and use.

\section{Activity analysis}

In order to collect data on the actual performance and internal variability of the system, indepth interviews were conducted with the head physician and the head nurse, seven nurses, eight physicians and one healthcare assistant. Categorical-type content analysis was applied to interview transcripts, with a view to detecting the most stressful situations. On the basis of the data collected from interviews, several observation phases were conducted jointly by two researchers, expert in physical and organisational ergonomics respectively, in order to integrate different perspectives. Particularly, the patient arrival and reception phase was observed.

\section{Results}

Here is a presentation of some of the critical elements detected in both phases of analysis: 


\section{Physico-environmental analysis}

- The station desk height obstructs the patient overview (Fig. 2), which nurses consider essential to get a full picture of the patient and his/her problems. Users'anthropometric variability has not been taken into account.

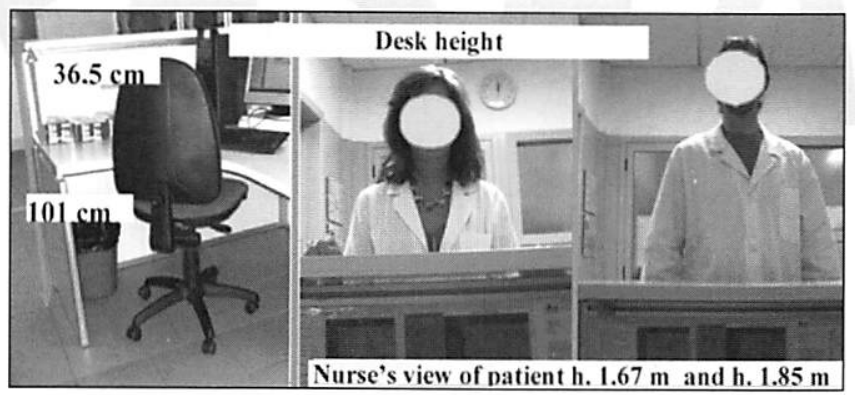

Fig. 2. The desk is too high, which is not consistent with patients' anthropometric variability and makes the triage station operator's observation difficult.

- The main entrance to the triage station is a mirror door not only externally (for the sake of patients'privacy), but also internally (Fig. 3). This means that the nurse cannot see who is ringing the bell.

- Unused tools cluttering up the desktop are not removed. The permanence of unused tools in already cluttered and scanty work spaces may be interpreted as an important indicator of a feeling of emergency relating not only to users'characteristics, but also to a chronic feeling of "being rushed for time".

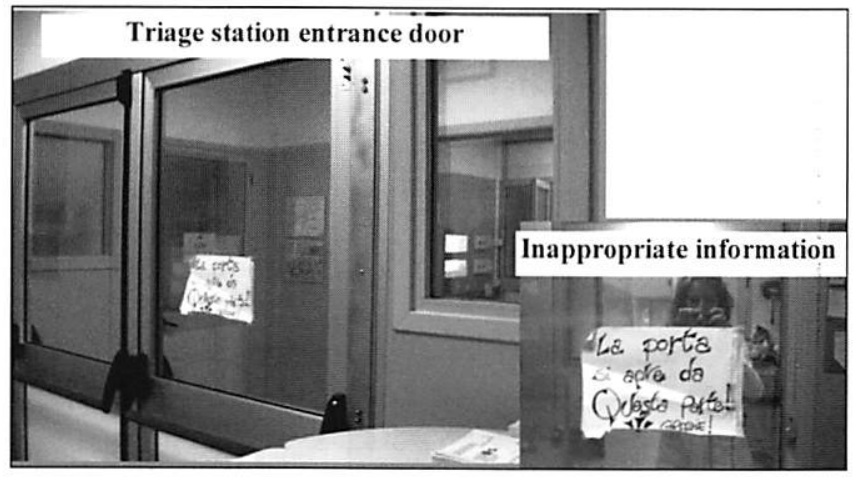

Fig. 3. The triage station entrance door is a mirror door even internally, which prevents the nurse from seeing who is ringing the bell. In addition, the information on how the door can be opened is inappropriate.

\section{Activity analysis}

- The necessary information to help the patient use the service appropriately is missing or is given inappropriately.

- Nurses have to cope with critical situations physicians are not aware of. Physicians, for example, close the door fronting the internal corridor to get more privacy, but with the door closed nurses cannot check the patients waiting in the corridor, unless they leave the triage station.

In order to give the operators some feedback on the data emerged from this analysis and to promote discussion and participation with a view to possible improvements, three discussion groups were conducted. The first two groups were homogeneous, the third one was mixed, open to all operators. These meetings allowed a reflection on the possibility of changing critical aspects previously taken for granted and of recognising the scarce homogeneity of some pragmatic choices. This gave rise to the need of establishing an integrated viewpoint on the system. Through the mixed discussion group the establishment of a common view of the system was attempted, by analysing different problems on the one hand, while emphasising the positive aspects to appeal to for possible future improvements on the other.Within a shared change-oriented perspective, the intervention priorities and the best solutions were thus identified.

\section{Discussion}

In the study presented above, the integration of different kinds of competence - in physical, cognitive and organisational ergonomics - allowed the identification of the psychological meaning of environmental aspects (such as the unused but not removed tools on the desktop as a trace of cognitive overload) and the repercussion of organisational aspects on the physical plane (such as the additional biomechanical load, caused by the need for performing more than one task simultaneously). The aspects on which redesigning should be focused were outlined through the active participation of the operators. The whole intervention was developed with the aim of shaping environments, tools and organisations capable of supporting and enhancing the operators'competence, to their own and the patient's advantage.

\section{References}

Adriaenssens J., de Gucht V.,Van der Doef M., Maes S. 2011. Exploring the burden of emergency care: predictors of stresshealth outcomes in emergency nurses. J. Adv. Nurs. 67(6): 1317-1328.

Carayon P., Smith M.J. 2000.Work organization and ergonomics. Applied Ergonomics, 31:649-662.

European Agency for Safety and Health at Work 2010. European survey on enterprises on new and emerging risks. European Union, http://osha.europa.eu.

Smith M.J., Carayon-Sainfort P. 1989. A balance theory of job design for stress reduction. Int. J. Ind. Ergonom., 4:67-79.

Thomson R. M. 1972. Design of multi-man machine work area. In: Van Cott H.P., Kinkade R. (Eds.), Human engineering guide to equipment design. U.S. Government Printing Office, Washington D.C.: $419-467$. 